Nuntius Antiquus, Belo Horizonte, v. 13, n. 1, p. 205-226, 2017

\title{
Treslendo a citação (República): de Platão a Homero
}

\section{Misreading the Quotation (Republic): From Plato to Homer}

Rafael Guimarães Tavares Silva

Universidade Federal de Minas Gerais, Belo Horizonte, Minas Gerais / Brasil gtsilva.rafa@gmail.com

Resumo: A citação é normalmente entendida como prática discursiva por meio da qual é possível estabelecer um diálogo entre diferentes textos e contextos, em tom polêmico ou harmônico, apto a suscitar novas ideias e desenvolvimentos teóricos. A fim de problematizar essa noção básica, retomo algumas das teses de Bakhtin acerca de uma compreensão dialógica da linguagem - em sua crítica contumaz aos modelos linguísticos então vigentes, de base psicológica ou estruturalista. Na sequência, proponho novas considerações sobre as formas mais recorrentes de citação, a partir de um expediente esboçado por Antoine Compagnon - oferecendo um breve catálogo das mesmas - e avanço alguns juízos sobre textos que se valem da prática da citação, em paráfrase ou em remissão direta ao discurso de outrem, para elaborar suas próprias ideias. A partir desse catálogo original, revisito um caso clássico dessa tradição - Homero e Platão, sobretudo em seu tenso "diálogo", tal como delineado na República - e pretendo acenar para a possibilidade de uma "ética da leitura" que, por meio de uma "prática da leitura", respeite o texto de outrem nas suas especificidades textuais e contextuais. É certo que um respeito absoluto a essas especificidades é impossível, mas gostaria de sugerir que qualquer ética - e uma "ética da leitura" não poderia ser diferente - só tem alguma chance de se dar efetivamente nos limites dessa impossibilidade mesma.

Palavras-chave: citação; Bakhtin; filosofia da linguagem; Platão; Homero. 
Abstract: The quotation is normally understood as a discursive practice that makes it possible to establish a dialogue between different texts and contexts, with a polemic tone or with a harmonic one; a dialogue able to evoke new ideas and theoretic developments. In order to problematize this basic scholarly practice, I retake some of Bakhtin's thesis about a dialogical comprehension of language - in his obstinate criticism of current linguistic models, with their psychological or structuralist approaches. Accordingly, I propound new considerations about the most recurrent forms of quotation, based on a device delineated by Antoine Compagnon, providing a brief catalogue of the types of citation, and I also present some judgments about texts that employ it, be it in paraphrase or in a direct remission to someone else's discourse, to elaborate new ideas. From this original catalogue, I revisit a classical case of this tradition - Homer and Plato, mainly in their tense "dialogue" as it is delineated in the Republic. By doing so, I intend to indicate the possibility of a "reading ethics". Such ethics would mean that through the system of a "reading practice" someone else's text would be respected in its textual and contextual specificities when used in citation. It is clear that an absolute respect for such specificities is impossible, but I would like to suggest that any ethics - and "reading ethics" could not be different - only have a chance of taking place effectively within the limits of this impossibility itself.

Keywords: quotation; Bakhtin; philosophy of language; Plato; Homer.

Recebido em: 1 de novembro de 2016.

Aprovado em: 17 de maio de 2017.

No âmbito de um estudo sobre uma poética de Platão, analisei o emprego de certa citação homérica no diálogo Críton, começando minha análise com as seguintes palavras:

O recurso da citação sempre foi imprescindível para o desenvolvimento de um lógos capaz de se estabelecer explicitamente enquanto diálogo, não 
apenas com seu próprio tempo, mas com a tradição que o precede. Quer tenha sido movida por intenções agônicas, ou por uma reverência quase hierofântica com relação a determinados autores, toda a tradição epistemológica foi construída a partir do retorno às palavras de precursores eleitos para uma nova miseen-scène (SILVA, 2015, p. 174).

Mesmo que eu ainda concorde, em linhas gerais, com essa proposição - e os jogos implicados por ela -, acredito ser necessário retomá-la e evidenciar as diferenças advindas de novas leituras e textos. Desejo desdobrar algo que aí se apresenta de forma ainda incipiente, qual seja, a diversidade de funções que uma citação pode assumir no interior de um determinado lógos. Para isso, partirei de uma concepção de linguagem que a trabalhe no interior de uma lógica dialógica, avançarei um catálogo das formas mais recorrentes de citação e trabalharei alguns trechos a partir desses passos iniciais.

A intuição básica acerca da natureza dialógica da linguagem intuição presente de forma velada nas palavras de minha própria citação com que inicio este texto - encontra uma de suas expressões mais acabadas na filosofia da linguagem do círculo de Bakhtin. Ainda que não seja meu intuito retomar todas as implicações desse pensamento, é importante lembrar que, partindo dos trabalhos de Marx, são retomadas de forma crítica as teses linguísticas das duas principais tendências teóricas nesse campo no início do séc. XX: o subjetivismo idealista (tal como preconizado principalmente por Humboldt e Vossler) e o objetivismo abstrato (conforme as propostas de Saussure). ${ }^{1} \mathrm{O}$ principal argumento avançado contra tais tendências é o fato de elas não levarem em conta a natureza social da enunciação, concentrando-se de forma quase exclusiva

\footnotetext{
${ }^{1}$ A exposição dessas duas orientações do pensamento filosófico-linguístico se dá no capítulo 4 de um livro de atribuição duvidosa, Marxismo e filosofia da linguagem: originalmente atribuído a Volochinov, embora tenha sido posteriormente reconhecido como obra do próprio Bakhtin (BAKHTIN [VOLOCHINOV], 1995, p. 69-89). A submissão dessas duas orientações linguísticas a uma análise profundamente crítica é desenvolvida no capítulo 5 do mesmo livro (BAKHTIN [VOLOCHINOV], 1995, p. 90-109).
} 
seja nas condições da vida psíquica individual de um sujeito falante, seja num sistema linguístico abstrato (BAKHTIN [VOLOCHINOV], 1995, p. 109). A fim de desenvolver uma teoria mais apta a explicar certos fenômenos linguísticos, a nova teoria proposta define o seguinte:

De fato, a forma linguística [...] sempre se apresenta aos locutores no contexto de enunciações precisas, $o$ que implica sempre um contexto ideológico preciso. Na realidade não são palavras o que pronunciamos ou escutamos, mas verdades ou mentiras, coisas boas ou más, importantes ou triviais, agradáveis ou desagradáveis, etc. A palavra está sempre carregada de um conteúdo ou de um sentido ideológico ou vivencial. É assim que compreendemos as palavras e somente reagimos àquelas que despertam em nós ressonâncias ideológicas ou concernentes à vida. (BAKHTIN [VOLOCHINOV], 1995, p. 95. Grifos do autor).

A partir de tal concepção, é certo que a imprescindível dimensão relacional da linguagem se evidencia - na medida em que todo enunciado passa a poder ser entendido como uma réplica no interior de um diálogo -, e a importância dos contextos de enunciação vem à tona. ${ }^{2}$ Talvez por isso Bakhtin se volte, no fim de seu livro sobre filosofia da linguagem, para a questão do "discurso citado" e desenvolva uma série de juízos dos quais me afasto na medida em que seu principal interesse lá é o texto ficcional, enquanto o meu aqui é pensar a prática da citação textual num sentido mais amplo. Ainda assim, gostaria de me perguntar se é toda citação que institui um diálogo efetivo no coração do discurso ou se certos discursos, mesmo parecendo instituir uma relação dialógica por meio da citação, permanecem encerrados em si mesmos de forma monológica.

\footnotetext{
${ }^{2}$ Essa concepção está presente também em textos posteriores do autor, sendo constitutiva de seu pensamento. No livro Esthétique et théorie du roman, ele afirma: "Un énoncé vivant, significativement surgi à un moment historique et dans un milieu social déterminés, ne peut manquer de toucher à des milliers de fils dialogiques vivants, tissés par la conscience socio-idéologique autour de l'objet de tel énoncé et de participer activement au dialogue social" (BAKHTINE, 1978, p. 100). No texto "Toward a Methodology for the Human Sciences", a expressão "contextual meaning" tem um papel básico para sua compreensão da linguagem e da comunicação (BAKHTIN, 1986, p. 292-410).
} 
Toda citação consiste, basicamente, num enunciado que - emitido num determinado contexto, sobre um determinado tema, a partir de um determinado acento apreciativo - é deslocado para um novo contexto, sendo possivelmente sobre um novo tema, a partir de um novo acento apreciativo, além de provavelmente vir envolto numa determinada orientação apreciativa (BAKHTIN [VOLOCHINOV], 1995, p. 128136). ${ }^{3}$ Na medida em que diálogo traz a noção de interação entre dois ou mais discursos, uma citação é dialógica quando - ao reaver o tema de um enunciado anterior - situa tal enunciado no interior de seu primeiro contexto de enunciação e faz com que o deslocamento a um novo contexto suscite um novo tema. A interação entre os temas no interior de uma mesma enunciação é o que caracteriza o dialogismo possivelmente instituído pela citação. Que este suscitar se dê numa relação agônica ou reverente para com o outro discurso é indiferente do ponto de vista da criação de um efeito dialógico: seguindo ainda a nomenclatura proposta em Marxismo e filosofia da linguagem, isso a que chamo de orientação apreciativa determina apenas o posicionamento de um discurso com relação ao outro - ao discurso citado - da mesma forma como um falante se posiciona diante do outro num diálogo.

Por conta do que ficou dito acerca do discurso que se faz dialógico por meio da citação, resta claro que também é possível citar de maneira monológica. Haverá monologismo sempre que - seja por adulterar o próprio enunciado de uma citação, seja por ignorar seu contexto de enunciação - um discurso citar um discurso anterior sem suscitar uma interação temática efetiva entre eles.

Retomando um jogo desenvolvido em parte por Antoine Compagnon, em seu livro $O$ trabalho da citação, ${ }^{4}$ proponho a seguir um breve catálogo original (ainda que não exaustivo) sobre os diferentes modos por que uma citação pode se impor num discurso monológico:

\footnotetext{
${ }^{3}$ Além disso, vale lembrar aqui algo que afirma Bennington (1991, p. 83) e que me ajudou a pensar a lógica da citação desde minhas primeiras considerações: "On peut toujours citer hors contexte. On cite d'ailleurs par définition hors contexte. Aucune nécessité ne préserve un énoncé quelconque d'être prélevé de 'son' contexte et greffé sur un autre [...]". ${ }^{4} \mathrm{O}$ autor promove um jogo linguístico entre citação, solicitação e excitação, mas não desenvolve esse expediente para além de um jogo local (COMPAGNON, 2007, p. 24-29).
} 
i. adulterando o próprio enunciado e ignorando seu contexto de enunciação:

a) se sua orientação apreciativa for agônica, será um atrocitar;

b) se for reverente, será um felicitar;

ii. adulterando o próprio enunciado, mas atentando a seu contexto de enunciação:

c) se sua orientação apreciativa for agônica, será um incitar;

d) se for reverente, será um excitar;

iii. mantendo o mesmo enunciado, mas ignorando seu contexto de enunciação:

e) se sua orientação apreciativa for agônica, será um crocitar;

f) se for reverente, será um ressuscitar.

A adulteração do próprio enunciado pode ser provocada pela supressão, introdução ou substituição de certos termos importantes do enunciado citado. A paráfrase e a citação por meio de discurso indireto, embora sejam formas que se prestam com mais facilidade a tais adulterações, não necessariamente as implicam: é possível parafrasear ou citar em discurso indireto respeitando o enunciado e o contexto de enunciação do discurso do outro. Quando tal respeito se dá - seja em discurso direto, seja em paráfrase ou discurso indireto -, a citação será sempre um suscitar.

A fim de pôr à prova essa sucinta teorização sobre os diferentes modos de citar monologicamente, desejo partir da análise das estratégias empregadas por um influente pensador helênico antigo e propor uma breve reflexão sobre o fenômeno que se verifica ainda entre autores contemporâneos. Com isso não pretendo avançar uma comparação entre os dois momentos - ou sugerir algum tipo de analogia entre os textos e 
os contextos da antiguidade helênica e da contemporaneidade ocidental ${ }^{5}$ -, mas indicar a possibilidade de constituição de um éthos responsável perante o discurso do outro: minhas leituras, desde a antiguidade helênica até a contemporaneidade e além, pretendem evidenciar que todo desenvolvimento democrático da linguagem e do conhecimento - em sua abertura à alteridade - se dá por meio do diálogo. ${ }^{6}$ Meu movimento de teorização abre-se, conscientemente, à possibilidade de ser acusado de envolvimento numa contradição performativa, na medida em que propõe uma arriscada reflexão metalinguística capaz de se voltar contra si própria, mas acredito que toda tentativa de suscitar um debate vivo sobre o compromisso ético da leitura seja digna de vir à tona.

Lerei a obra de Platão. Não é por acaso que, para pôr à prova o catálogo de maneiras monológicas da citação, eu me volte de preferência para as obras que Bakhtin considerava fazerem parte da produção madura do filósofo ateniense. ${ }^{7}$ Conforme o teórico russo, o caráter dialógico da obra de Platão estaria presente sobretudo naqueles que eram considerados seus primeiros diálogos, nos quais a influência de Sócrates seria mais perceptível, enquanto em sua obra tardia haveria uma propensão monológica responsável por minar a própria forma do

\footnotetext{
${ }^{5}$ Compagnon, no capítulo "A regulação clássica da escrita ou o texto como homeostase", propõe uma compreensão diacrônica do desenvolvimento da prática da citação desde a antiguidade até a modernidade, como mecanismo de controle do discurso (controle externo, interno ou ausente). Ainda que seu tratamento seja um tanto quanto superficial, dada a vasta extensão temporal do material lido, sua proposta tem o mérito de uma rápida inteligibilidade da história geral desse desenvolvimento (COMPAGNON, 2007, p. 96-103).

${ }^{6}$ Sobre a prática da citação na antiguidade, cumpre evocar o que diz Compagnon: "Não há, nem em grego, nem em latim, nenhuma palavra que possua o sentido exato da citação (como prática discursiva específica) tal como o entendemos no francês e como o traduzimos, sem rodeios, para o inglês ou para o alemão. Sem inferir da ausência da palavra a ausência da prática, o que faltava na antiguidade era, em todo caso, uma categoria que permitisse pensar, enunciar tal prática como unificada de maneira institucional" (COMPAGNON, 2007, p. 62).

${ }^{7}$ Autores recentes tendem a modalizar um pouco essas distinções entre um Platão, a princípio, eminentemente socrático e, na sequência, um Sócrates profundamente platônico. Para breves considerações e a indicação bibliográfica acerca disso, ver ZAPPEN, 2004, p. $2-6 ; 12-15 ; 20-21$.
} 
"diálogo socrático" ${ }^{8}$ Característico dessa propensão monológica seria o modo de composição da República, diálogo em que inúmeros trechos de outros poetas e pensadores são citados ou aludidos pelas personagens, principalmente por Sócrates (entendido aqui sempre como personagem do diálogo). ${ }^{9}$ Em todo caso, com relação às obras de inúmeros pensadores da tradição helênica (poética e filosófica), é preciso ter em mente que Platão as treslê: suas proposições não são o fruto de "mal-entendidos" ou de interpretações apressadas, mas de uma prática deliberada de manipulação da citação como instrumento de embates pedagógicos (com consequências epistemológicas, políticas, filosóficas, entre outras). ${ }^{10}$

Em Rep., III, 390a-b, no interior da crítica ao conteúdo dos poemas tradicionais, do ponto de vista da pedagogia almejada para a classe de phýlakes ("guardas") da pólis criada em lógos, Sócrates propõe a seguinte consideração:

E isso? Pôr o mais sensato dos homens a dizer que a coisa que lhe parece mais bela no mundo é estar junto de mesas repletas/de pão e carnes, e o escansão haurir o vinho/ dos crateres, para o vir deitar nas

8 Nas palavras de Bakhtin (1970, p. 129): “Chez Platon, dans les dialogues de la première et de la deuxième périodes de son oeuvre la reconnaissance du dialogue comme nature de la vérité se maintient encore dans son univers philosophique même, quoique sous une forme affaiblie. C'est pourquoi le dialogue de ces périodes ne se transforme pas encore chez lui en simple procédé d'exposition d'idées toutes faites (dans des buts pédagogiques) et Socrate ne se transforme pas encore en 'maître'. Mais dans la dernière période de l'oeuvre de Platon ce n'est plus le cas; le système de monologue qui en constitue le contenu commence à détruire la forme du "dialogue socratique". 9 A questão já foi colocada nos seguintes termos por um estudioso da relação entre o diálogo socrático e Bakhtin: "In the rhetorical/philosophical tradition of Plato and Aristotle, Socrates is the practioner of a dialectical/dialogical method that appears intermixed with the dialectic and rhetoric of the Gorgias, becomes transformed into the dialectical rhetoric of the Phaedrus, and disappears entirely from the ideal state of the Republic" (ZAPPEN, 2004, p. 17-8).

${ }^{10}$ Muitas foram as razões aduzidas para que Platão procedesse a esses "embates pedagógicos". Para algumas das interpretações acerca disso, ver Jaeger (2013, p. 7551005); Havelock (1963); Levin (2001); Destrée; Herrmann (2011). 
taças. Parece-te isto apropriado para que um jovem, ao ouvi-lo, se incline ao domínio de si mesmo? (PLATÃO, Rep., III, 390a-b). ${ }^{11}$

O que está implicado por isso - a partir de uma citação a $O d$., IX, 8-10 - é que "o mais sensato dos homens", Odisseu, estaria reduzindo a beleza da existência à mera possibilidade de saciar à vontade os apetites da mesa. Compreendida no interior da crítica mais geral à poesia, tal como se desdobra ao longo da República, a sugestão é a de que o poeta estaria instituindo um modelo de comportamento absolutamente incapaz de praticar a temperança necessária a um verdadeiro guarda. Ora, quando volto ao trecho da Odisseia de onde a citação fora extraída, constato que o início do discurso de Odisseu foi mutilado e aquilo que implicaria a dimensão eminentemente social e política de seu posicionamento, extirpado:

Alcino poderoso, excelente entre todos os povos, na verdade é coisa bela ouvirmos um aedo como este, cuja voz se assemelha à dos deuses. Pois afirmo que não há na vida finalidade mais bela do que quando a alegria domina todo o povo, e os convivas no palácio ouvem o aedo sentados em filas; junto deles estão mesas repletas de pão e de carnes; e o serviçal tira vinho puro do vaso onde o misturou, e serve-o a todos em taças. É isto que me parece a melhor coisa de todas. (HOMERO, Od., IX, 2-11). ${ }^{12}$

\footnotetext{
${ }^{11}$ As traduções da República são de Maria Helena da Rocha Pereira (ainda que a versão de Jacó Guinsburg tenha sido consultada e alterações tenham sido feitas

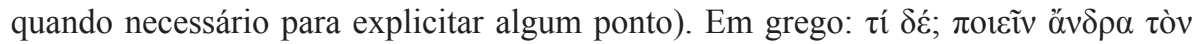

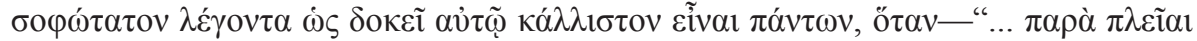

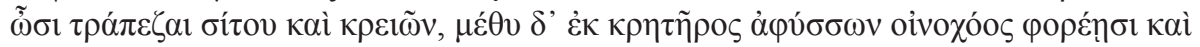

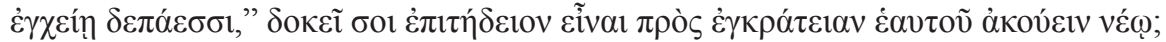
${ }^{12}$ As traduções dos poemas homéricos são de Frederico Lourenço. Em grego: 'A $\lambda \kappa i ́ v o \varepsilon$

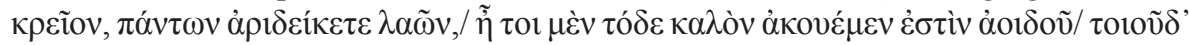

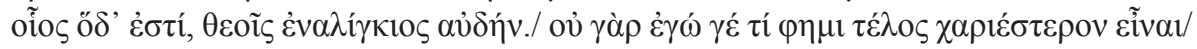

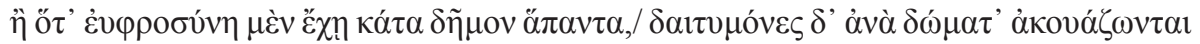

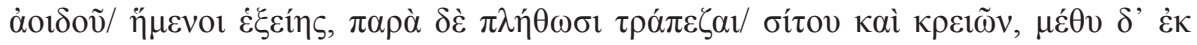

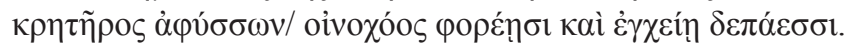


Seria necessário explicitar de forma mais delongada o que entendo pela "dimensão eminentemente social e política" do discurso de Odisseu, ${ }^{13}$ mas o que importa ressaltar aqui é que - da perspectiva da minha breve tipologia citacional - Sócrates atrocita o trecho homérico, ou seja, cita-o adulterando seu enunciado (por supressão) e ignorando (ou fingindo ignorar) seu contexto de enunciação. O efeito obtido por essa estratégia é chapar o que parece subjazer aos versos homéricos, homogeneizando um enunciado dotado de certas nuances a fim de incorporá-lo monologicamente como se pudesse ser antagonizado de maneira descomplicada pelo discurso de Sócrates. ${ }^{14}$ Estratégia semelhante é empregada também em Rep., V, 468d-e, embora a orientação apreciativa já não seja agônica, mas reverente. No contexto em questão, Sócrates esboça as honras de que os guardas seriam dignos pelo bom desempenho de suas funções bélicas e já não vê problemas em tentar assegurá-las por meio de um recurso à autoridade do mesmo corpus de poesia tradicional que anteriormente expurgara:

Mas, segundo Homero, é justo honrar os jovens valentes com prêmios desse género. Pois também Homero contou que Ájax, "tendo alcançado fama" no combate, "foi honrado com um lombo inteiro", como sendo esta a distinção adequada a um homem jovem e corajoso, pois com ela aumentaria simultaneamente o seu prestígio e força. (PLATÃO, Rep., V, 468d-e). ${ }^{15}$

\footnotetext{
${ }^{13}$ Segundo um estudioso do assunto: "Além do reconhecimento do papel do aedo no banquete (algo que em Platão tenderia a ser substituído pela filosofia), Ulisses aqui, como se prefigurando Sólon (cf. 4 W, 7-10), exalta o efeito de harmonização social proporcionado pelo banquete ('quando a alegria domina todo o povo') como 'a mais

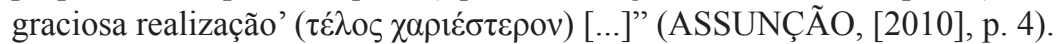

${ }^{14}$ Para uma leitura mais detida dos deslocamentos promovidos por essa citação de Sócrates, cf. Assunção, [2007], p. 11; Assunção, [2010], p. 4-5.

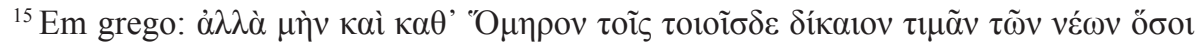

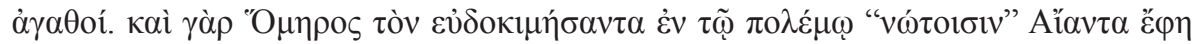

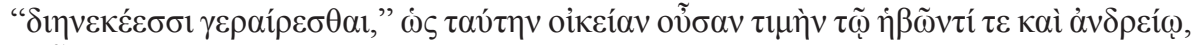

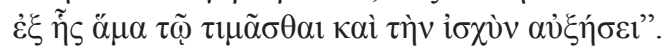


O que está implicado nessa passagem é a sugestão de que os guerreiros moços e valentes deveriam ser recompensados pela coletividade da qual fazem parte (isto é, por aqueles responsáveis pelas tarefas de guarda e justiça no interior da pólis imaginada por Sócrates). A um primeiro olhar, não parece haver qualquer contradição entre o que é citado pelo filósofo e o trecho da Ilíada (VII, 321-2), no qual, depois do difícil combate contra Heitor, os guerreiros vão se banquetear e Ájax, que fizera face ao troiano com amplas demonstrações de coragem e valor, recebe um destaque especial: "A Ájax honrou com o lombo contínuo do boi/ o herói, filho de Atreu, Agamêmnon de vasto poder". ${ }^{16}$

O problema, contudo, é que Sócrates apaga o caráter particular do ato de Agamêmnon, da sua doação pessoal em honra ao mérito de um guerreiro específico que se destacou em combate. Ao apagar esse aspecto de ato pessoal, por meio de uma indeterminação do responsável pela concessão de honra a Ájax, aquilo que fica sugerido por Sócrates seria que a própria comunidade se responsabilizaria por tal reconhecimento. $\mathrm{O}$ efeito obtido por seu discurso é o de apagar as diferenças entre os versos homéricos e o que é defendido pelo filósofo - qual seja, a existência de uma comunidade que honra e premia seus mais destacados guerreiros por suas atividades em prol desta mesma comunidade. Homogeneíza-se o enunciado por meio de sua adulteração, em desrespeito a seu contexto de enunciação, a fim de incorporá-lo monologicamente, como se ele não problematizasse algumas questões subjacentes ao discurso de Sócrates. Daí se compreender que o filósofo felicita os versos homéricos.

Retornando ao trecho da crítica ao conteúdo dos poemas tradicionais, nos livros II e III da República, há um momento em que Sócrates condena de maneira explícita a avareza pretensamente sugerida pelo comportamento de Aquiles na Ilíada. O filósofo propõe o seguinte:

nem prezaremos Aquiles nem concordaremos que ele seja tão ambicioso que aceite dádivas de Agamémnon, e que entregue um cadáver depois de

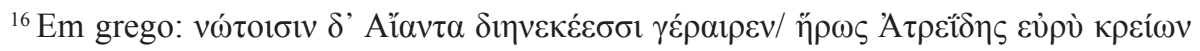
А $\gamma \alpha \mu \varepsilon ́ \mu \nu \omega \nu$. 
receber o resgate, sem que de outro modo estivesse disposto a fazê-lo. (PLATÃO, Rep., III, 390e). ${ }^{17}$

A alusão parece ser a dois eventos da Ilíada, espalhados por alguns trechos do poema (XIX, 278-81; XXIV, 502, 505-556, 594). Um retorno a esses trechos demonstra claramente a forma enviesada com que o comportamento de Aquiles é descrito - ainda que, para fazê-lo, leve em consideração o contexto imediato nos quais essas menções são feitas (uma vez que contextualiza o comportamento de Aquiles com as cenas em que o herói o teria manifestado). Em sua análise acerca do que está envolvido pelo discurso de Sócrates ao remeter à Ilíada, Penelope Murray propõe o seguinte:

Aquiles recebe os dons de Agamêmnon em $I l$. 19.278-81, apesar de mais cedo neste canto (em 146-153) ele deixar claro que retornará ao combate independentemente de se Agamêmnon os der ou não. Príamo oferece a Aquiles o resgate em troca do corpo de Heitor em Il. 24.501-502 e 555-556, mas em 560-570 Aquiles diz que ele restituirá o corpo de qualquer modo em conformidade com a vontade de Zeus. A caracterização de Aquiles por Platão como philokhrématos não é, portanto, estritamente acurada. (MURRAY, 1997, p. 165). ${ }^{18}$

Daí se compreender que Sócrates incita contra o trecho homérico, ou seja, cita-o ignorando seu enunciado, ainda que pareça atentar para seu contexto de enunciação. $\mathrm{O}$ efeito obtido por essa estratégia é

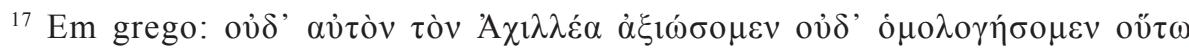

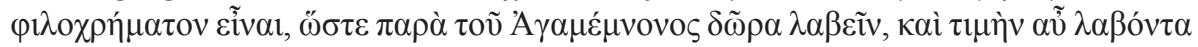

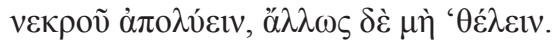

${ }^{18}$ Tradução de Teodoro Rennó Assunção (ASSUNÇÃO, [2007] p. 13). Em inglês: “Achilles receives Agamemnon's gifts at $\boldsymbol{I l} .19 .278$ 81, although earlier in the book at 146-53 he makes it clear that he will return to battle regardless of whether Agamemnon gives them or not. Priam offers Achilles ransom in return for Hector's body at II. 24.4012 and 555-6, but at 560-70 Achilles says that he will give back the body anyway in accordance with Zeus' wishes. P[1ato]'s characterisation of Achilles as $\varphi \imath \lambda \sigma \chi \rho \eta \dot{\mu} \mu \tau \sigma \varsigma$ is therefore not strictly accurate". 
projetar uma noção inexistente nos versos homéricos, desconfigurando um enunciado a fim de incitar um posicionamento contrário a ele (ou ainda, de se incitar contra tal enunciado): mesmo que tal dicotomização tenha ares de um tipo de interação entre os discursos, trata-se ainda de um discurso monológico.

Uma estratégia semelhante é utilizada em Rep., X, 607b, com uma orientação apreciativa reverente. No contexto em questão, Sócrates conclui os argumentos de seu último ataque contra a poesia mimética e, aderindo reverencialmente a uma pretensa tradição filosófica que se contraporia a certa tradição poética, afirma o seguinte:

Aqui está o que tínhamos a dizer, ao lembrarmos de novo a poesia, por, justificadamente, excluirmos da cidade uma arte desta espécie. Era a razão que a isso nos impelia. Acrescentemos ainda, para ela não nos acusar de uma tal ou qual dureza e rusticidade, que é antigo o diferendo entre a filosofia e a poesia. (PLATÃO, Rep., X, 607b). ${ }^{19}$

Ainda que Sócrates cite alguns trechos de poetas desconhecidos, ele não retoma os enunciados "filosóficos" que testemunhariam também da parte da "filosofia" a antiguidade de tal dissidência. Com relação a isso, há algum consenso entre os estudiosos de que a referência seja, entre outros possíveis, a Xenófanes, Heráclito e Empédocles. ${ }^{20} \mathrm{O}$ problema é que, para além da crítica de fato apresentada por tais "filósofos" contra determinados poetas - Homero e Hesíodo sobretudo -, alguns deles escreveram suas obras "filosóficas" em versos, empregando formas e métricas de uma tradição reconhecidamente poética. O problema é que

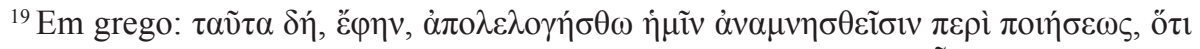

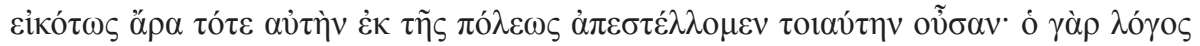

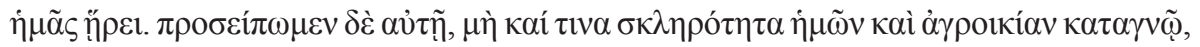

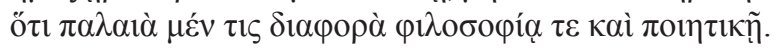

${ }^{20}$ Nos comentários de Daniel Rossi Nunes Lopes à tradução de Jacó Guinsburg da República: "Platão pode estar aludindo às críticas à poesia e aos poetas feitas por filósofos que o precederam, como Xenófanes, Heráclito e Empédocles [...]" (PLATÃO, 2014, p. 395, nota 48).
} 
Sócrates - mesmo considerando o contexto possivelmente "filosófico" em que tais considerações teriam sido desenvolvidas - ignora seus enunciados propriamente ditos. O efeito obtido por essa estratégia é apagar uma nuance que deveria ser levada em conta por toda interpretação da obra de "poetas filósofos" (ou de "filósofos poetas"). Por mais que pareça haver uma relação entre aquilo que é citado de forma desfigurada e o próprio discurso que traz tal citação, na verdade há apenas o monologismo de um discurso excitado. Daí se compreender que o filósofo excita aquela "tradição filosófica" em direção a si mesmo (ou ainda, excita-se até tal enunciado). Em Rep., III, 386c, mais uma vez no interior da crítica ao conteúdo dos poemas tradicionais, Sócrates propõe a seguinte consideração:

Logo, teremos de expungir, a começar nestes versos, todas as afirmações desta espécie: Antes queria ser servo da gleba, em casa/ de um homem pobre, que não tivesse recursos, / do que ser agora rei de quantos mortos pereceram [...]. (PLATÃO, Rep., III, 386c). ${ }^{21}$

Aqui, mais uma vez, se trata de uma citação por meio da qual Sócrates sugere que os modelos de comportamento estabelecidos pelos poetas em geral - mais especificamente pelos poemas homéricos - não seriam próprios para os guardas idealizados por ele, na medida em que esses deveriam prezar pelo cumprimento de suas funções acima da própria vida (algo que pareceria contrariar o que diz a psykhê de Aquiles no trecho citado, em Od., XI, 489-491). Embora a citação mantenha o mesmo enunciado daquilo que cita, sua desatenção ao contexto maior do conjunto de valores dos poemas homéricos oferece-lhe a possibilidade de projetar uma moralidade que não parece corroborada pelo comportamento efetivo de nenhum de seus heróis. Um estudioso desses assuntos, no âmbito de um estudo justamente sobre as imagens de Odisseu e Aquiles no livro III da República, afirma o seguinte:

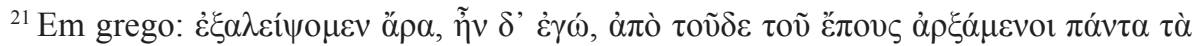

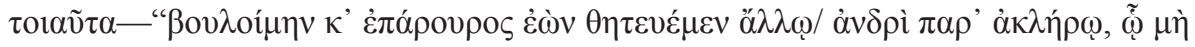

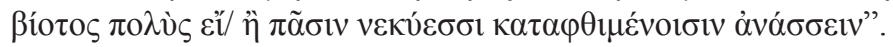


Poderíamos, no entanto, contrapor à tese platônica de que uma tal representação homérica do post-mortem deve levar ao medo da morte e a um apego covarde à vida o conjunto do comportamento dos heróis iliádicos (Aquiles, Heitor, Pátroclo, Sarpédon, Ájax, Ulisses, Diomedes e mesmo Agamêmnon em sua aristéia) que, mesmo partilhando a crença em uma tal representação (ou antes precisamente devido a ela), irão arriscar corajosamente a vida em combate. A consideração pessimista do post-mortem como infra-vida e a desta existência corporal como a única verdadeira levando aí não a uma valorização absoluta da vida, mas a uma escolha corajosa do mais nobre modo de viver, ou seja: combatendo corajosamente. (ASSUNÇÃO, [2007], p. 7).

Ou seja, a fala de Aquiles faz parte de um conjunto de representações responsáveis por salientar ainda mais claramente o valor de quem se dispõe ao combate de modo corajoso, na medida em que os riscos envolvidos por tal atividade dizem respeito não apenas à perda de uma situação favorável, mas ao desenvolvimento de uma terrível condição de existência. Assim sendo, Sócrates, embora mantenha o mesmo enunciado homérico em sua citação, ignora seu contexto de enunciação e, esvaziando o sentido daquilo que estaria implicado pela fala da psykhê de Aquiles, assimila-o a um discurso monológico, no qual cumpre mera função agônica. Daí se compreender que Sócrates apenas crocita os versos homéricos.

Um expediente comparável é empregado por Sócrates em Rep., VII, 516c, valendo-se curiosamente do mesmo trecho da Odisseia, embora sua orientação apreciativa já não seja agônica, mas sim reverente. Nesse novo contexto, Sócrates tergiversa sobre a situação do verdadeiro filósofo na pólis e - tal como disse pouco acima sobre suas considerações acerca das recompensas aos guardas no livro V - sua atitude hostil para com o repertório tradicional de poesia já não está presente, na medida em que, para assegurar certos comportamentos, ele não vê problema em recorrer à autoridade da tradição poética (daquela mesma que anteriormente fora expurgada pela discussão dos livros II e III). Ele afirma o seguinte: 
E as honras e elogios, se alguns tinham então entre si, ou prémios para o que distinguisse com mais agudeza os objectos que passavam, e se lembrasse melhor quais os que costumavam passar em primeiro lugar e quais em último, ou os que seguiam juntos, e àquele que dentre eles fosse mais hábil em predizer o que ia acontecer - parece-te que ele teria saudades ou inveja das honrarias e poder que havia entre eles, ou que experimentaria os mesmos sentimentos que em Homero, e seria seu intenso desejo "servir junto de um homem pobre, como servo da gleba", e antes sofrer tudo do que regressar àquelas ilusões e viver daquele modo? (PLATÃO, Rep., VII, 516c). ${ }^{22}$

Aqui, embora mantenha em linhas gerais o mesmo enunciado da psykhê de Aquiles da Odisseia (XI, 489-491), Sócrates mais uma vez ignora seu contexto, empregando uma citação que pode ser criticada segundo os mesmos moldes do que ficou dito acima: ao tomar tal fala como se fosse mera constatação de um éthos incentivado pelos poemas homéricos, sem levar em conta o fato de que é emitida por uma psykhê no âmbito de uma descida ao reino dos mortos [katábasis], Sócrates esvazia o sentido daquilo que estaria implicado contextualmente pelo poema. A consequência de tal expediente é a assimilação dos versos homéricos a um discurso monológico, no qual cumprem mera função de autoridade perante a qual se manifesta certa reverência (uma reverência certamente dúbia quando se leva em conta a ferocidade do escrutínio a que a poesia helênica tradicional é submetida ao longo de toda a República, sobretudo nos livros II, III e X). Em todo caso, para essa passagem é possível sugerir que Sócrates ressuscita os versos homéricos.

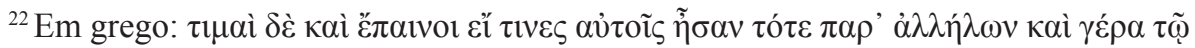

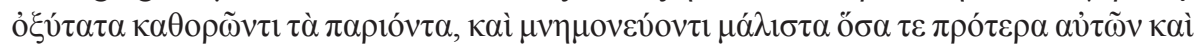

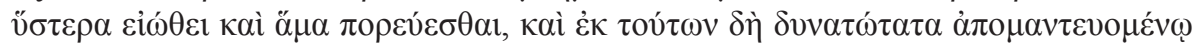

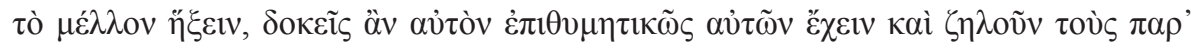

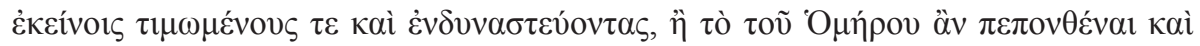

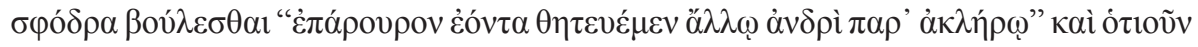

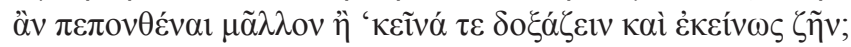


Todas estas são formas de citar o discurso do outro por meio de uma incorporação a um discurso monológico, ou seja, num discurso em que se restringe o espaço para o diálogo de fato, seja pela adulteração do enunciado citado, seja pela desatenção a seu contexto de enunciação: atrocitar, felicitar, incitar, excitar, crocitar e ressuscitar. Se essas formas de citar encontram sua manifestação mais recorrente e acabada nas obras que Bakhtin considerava as mais tardias do corpus platônico, a maneira dialógica de citar o discurso alheio, respeitando-o em seu enunciado e em seu contexto de enunciação, estaria presente sobretudo naqueles que eram tomados pelos primeiros diálogos socráticos: Eutífron, Apologia, Críton etc.

Em outra oportunidade analisei a complexidade implicada pela citação dialógica, oferecendo uma leitura especial da passagem de Críton 43d-44b, na qual Sócrates cita uma fala de Aquiles, extraída de uma passagem da Ilíada (IX, 363). Não poderei retomar os detalhes dessa leitura, mas destaco a parte mais teórica de minhas conclusões:

Por meio da análise de Críton, 43d-44b, defendemos a importância atribuível a uma leitura mais detida de trechos que se valem de citações. Se, por um lado, o contexto do qual a citação foi retirada deve ser levado em consideração pela nova leitura, bem como o trecho em que tal citação foi inserida, por outro, é importante considerar os deslocamentos operados por seu emprego. Ou seja, é preciso estar atento a (no mínimo) três "níveis" de leitura quando algum texto se vale de uma citação. Ainda assim, empregos mais complexos da citação podem exigir atenção a muitos outros níveis de leitura, a fim de que as várias associações propostas pelo texto possam ser compreendidas pelo leitor. (SILVA, 2015, p. 191). ${ }^{23}$

Nessas palavras, embora a teoria aqui avançada sobre as seis principais formas de citação monológica ainda não tivesse sido proposta, é possível entrever as razões para que a sétima forma de citação - justamente a citação dialógica - seja apta a suscitar tamanha

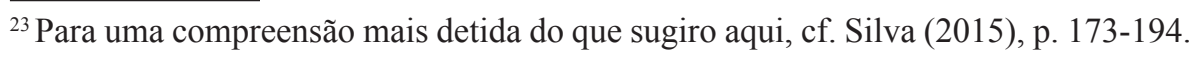


complexidade. Ao trazer o discurso do outro para o coração de seu próprio discurso, tal citação instala um diálogo temático de fato entre dois ou mais enunciados, nas intermitências entre dois ou mais contextos. Esse diálogo é que possibilita todo desenvolvimento da linguagem e do conhecimento a partir de uma abertura ao discurso do outro. ${ }^{24}$

Tal como afirmei inicialmente, pretendo indicar com minhas leituras - desde a antiguidade helênica até a contemporaneidade - a possibilidade de constituição de um éthos perante o discurso do outro, por meio de uma práxis atenta aos textos e contextos implicados por um apelo à alteridade (e não à autoridade). Ainda que eu não possa me voltar à prática da citação contemporânea - fenômeno muito complexo para ser tratado no âmbito de um pequeno artigo -, gostaria de indicar uma tendência cada vez mais comum na contemporaneidade (mesmo entre textos acadêmicos e com preocupações epistemológicas). Apesar de regras e princípios indicarem a necessidade de se ter atenção ao enunciado e ao contexto de enunciação sempre que se emprega uma citação, uma tendência monológica tem se dispersado com uma frequência cada vez maior hoje em dia, como seria possível sugerir com a indicação de alguns exemplos. ${ }^{25}$ Ainda que práticas e teorias de leitura desenvolvidas nas últimas décadas apontem a importância de se estabelecer um discurso

\footnotetext{
${ }^{24}$ Zappen, em seu livro sobre o renascimento do diálogo - de Sócrates a Bakhtin -, conclui sua introdução com as seguintes palavras: "[...] as I argue in my epilogue, dialogue as a Bakhtinian/Socratic testing, contesting, and creating of ideas is neither impossible nor inevitable but is merely possible and only possible in any medium if we are willing to hear and to engage in the ongoing exchange of voices in each of them" (ZAPPEN, 2004, p. 15).

${ }^{25} \mathrm{O}$ círculo de Bakhtin já o notava no início do séc. XX, quando a seguinte crítica era proposta: "Mesmo as ciências humanas desenvolveram uma tendência a substituir afirmações responsáveis acerca de um problema por uma descrição do estado atual das pesquisas na área, incluindo cálculo e adução indutiva do 'ponto de vista geralmente admitido nos nossos dias'; esse procedimento é mesmo algumas vezes considerado a melhor 'solução' possível de um problema. Em tudo isso manifesta-se a alarmante instabilidade e a incerteza da palavra ideológica. O discurso literário, retórico, filosófico, e o das ciências humanas tornam-se o reino das 'opiniões', das opiniões notórias, e mesmo nessas opiniões não é tanto o 'quê' mas o 'como' individual ou típico da opinião em causa que ocupa o primeiro plano” (BAKHTIN [VOLOCHINOV], 1995, p. 195-6).
} 
efetivamente dialógico, na medida de sua atenção aos textos e contextos lidos - tal como é recorrente nos métodos mais conscienciosos de close reading -, é curioso notar que muitos textos escritos pelos mais atentos leitores atualmente sejam vítimas de violentas tresleituras (ou ainda desleituras) monologizantes. ${ }^{26}$

É importante notar que não questiono o valor do mal-entendido como possibilidade de produção do conhecimento. Há mal-entendidos - em todos os campos das ciências: biológicas, exatas e humanas responsáveis por descobertas e desenvolvimentos verdadeiramente revolucionários em suas áreas de estudo e pesquisa. Ainda assim, proponho aqui um éthos de leitura que se funde numa práxis baseada num método, ou seja, proponho um método de práticas que seja capaz de fundamentar uma ética de leitura minimamente responsável perante o discurso do outro. Levando isso em conta, acharia suspeito se alguém sugerisse um método de práticas que a um só tempo partisse do malentendido como princípio básico e intentasse fundamentar nele uma ética responsável perante a alteridade. Minha proposta é suscitar uma reflexão sobre os modos de abertura do próprio discurso a um diálogo efetivo com o outro, a fim de que - para além das concordâncias ou discordâncias esboçadas nesse diálogo - um compromisso ético de leitura se revele minimamente possível a partir de um conjunto simples de práticas.

Retomo aqui minhas considerações iniciadas alhures. Sugerindo que meu plano de teorização das diversas práticas da citação tenha tecido novas formas de compreensão da linguagem e do conhecimento discursivo, penso que o leitor estará mais atento aos riscos implicados por um discurso que se imponha como monológico - riscos principalmente em seu desrespeito aos outros discursos, incorporados por ele - e poderá se abrir a uma corrente interessada em dar lugar à diversidade dos textos e contextos. Apesar da impossibilidade de um respeito absoluto à alteridade

\footnotetext{
${ }^{26}$ Alguns desses exemplos foram tratados por mim numa comunicação que teve lugar durante o XV Encontro da ABRALIC na UERJ em 2016, cuja transcrição - enriquecida pelo debate que se seguiu à exposição - será publicada nos anais do Congresso.
} 
solicitada na citação, ${ }^{27}$ acredito que toda e qualquer ética só terá alguma chance de se dar efetivamente nos limites de tal impossibilidade. Abrir um diálogo respeitoso no coração do próprio discurso é tornar possível essa impossibilidade: ainda que tal diálogo seja entre mim e eu mesmo, como quando começo um texto com uma citação minha e o encerro reafirmando acreditar "ser necessário retomá-la e evidenciar as diferenças advindas de novas leituras e textos".

Que nossas considerações sejam sustadas aqui, com a intuição reforçada de que dialogar é acolher o outro no coração do próprio lógos... ${ }^{28}$

\section{Agradecimentos}

Ao Prof. Dr. Teodoro Rennó Assunção (Faculdade de Letras da UFMG), pela oportunidade de voltar a dialogar sobre a República no primeiro semestre de 2016; e a Taís Freire de Andrade Clark, por fundamentar a textura e arrematar a contextura do presente artigo.

\section{Referências}

ASSUNÇÃO, T. R. Aquiles e Ulisses no livro III da República de Platão. In: COLÓQUIO PLATÔNICO: POLITEÍA, III, 3., 2007, Rio de Janeiro (artigo inédito).

\footnotetext{
${ }^{27}$ Conforme a lição do Pierre Menard de Borges (1971, p. 47-60), jamais é possível ter um respeito absoluto ao discurso do outro, uma vez que a própria repetição literal não se restringe a uma repetição de fato.

${ }^{28} \mathrm{O}$ tom metalinguístico das considerações de Bennington sobre a citação - justamente no que tangem à difícil tarefa de "sistematizar o pensamento de Jacques Derrida" ecoa também no que pretendemos ter imprimido neste texto sobre a prática da citação: "On voit tout de suite que ces guillemets ne suffisent pas pour rendre compte des difficultés qui accompagnent la citation et le respect de la signature de l'autre qu'elle devrait impliquer. Ce respect doit comporter un respect pour le contexte dans lequel on prélève le passage cité, et nous avons déjà vu que, dans la mesure où on cite toujours par définition hors contexte, un tel respect ne pourrait jamais être total. Et on peut toujours citer sans guillemets, ou pratiquer d'autres méthodes pour ne pas assumer entièrement ce qu'on écrit et signe" (BENNINGTON, 1991, p. 143-4).
} 
ASSUNÇÃO, T. R. Melhores pedaços de carne e taças cheias: o banquete homérico sob o signo da coragem em República V (468 d2-3 e 468 e1). In: COLÓQUIO PLATÔNICO: POLITEÍA, V, 5., 2010, Rio de Janeiro (artigo inédito).

BAKHTIN, M. [VOLOCHINOV]. Marxismo e filosofia da linguagem. São Paulo: Hucitec, 1995.

BAKHTIN, M. Toward a Methodology for the Human Sciences. In: . Speech Genres and Other Late Essays. Translated by Vern M. McGee. Edited by Caryl Emerson and Michael Holquist. Austin: University of Texas Press, 1986. p. 159-72.

BAKHTINE, M. Esthétique et théorie du roman. Paris: Gallimard, 1978. BAKHTINE, M. Problèmes de la poétique de Dostoïevski. Paris: L'Âge d'Homme, 1970.

BENNINGTON, G. Derridabase. In: BENNINGTON, G.; DERRIDA, J. Jacques Derrida. Paris: Éditions du Seuil, 1991. p. 5-292.

BORGES, J. L. Pierre Menard, autor del Quijote. In: . Ficciones. Madrid: Alianza Editorial Madrid, 1971. p. 47-60.

COMPAGNON, A. O trabalho da citação. Tradução de Cleonice P. B. Mourão. Belo Horizonte: Editora UFMG, 2007.

DESTRÉE, P.; HERRMANN, F.-G. (Ed.). Plato and the Poets. Leiden; Boston: Brill, 2011.

HAVELOCK, E. Preface to Plato. Cambridge; London: Belknap Press of Harvard University Press, 1963.

HOMER. Homeri Opera in Five Volumes. Oxford: Oxford University Press, 1920.

HOMERO. Ilíada. Tradução e prefácio de Frederico Lourenço. São Paulo: Penguin Classics; Companhia das Letras, 2013.

HOMERO. Odisseia. Tradução e prefácio de Frederico Lourenço. São Paulo: Peguin Classics; Companhia das Letras, 2011.

JAEGER, W. Paideía: a formação do homem grego. Tradução de Artur M. Parreira. 6. ed. São Paulo: WMF; Martins Fontes, 2013. 
LEVIN, S. The Ancient Quarrel Between Philosophy and Poetry Revisited: Plato and the Greek Literary Tradition. Oxford: Oxford University Press, 2001.

MURRAY, P. Plato on Poetry. Preface, introduction, and commentary in English with text in Greek. Cambridge: Cambridge University Press, 1997.

PLATÃO. A república de Platão. Obras I. 2. ed. Organização e tradução de Jacó Guinsburg, notas de Daniel Rossi Nunes Lopes. São Paulo: Perspectiva, 2014.

PLATÃO. A república. Introdução, tradução e notas de Maria Helena da Rocha Pereira. Lisboa: Fundação Calouste Gulbenkian, 2001.

PLATO. Platonis Opera. Ed. John Burnet. Oxford: Oxford University Press, 1903.

SILVA, R. G. T. Lendo a citação (Críton, 43d1-44b5): "Vou-me embora pra fértil Phthía...". Nuntius Antiquus, Belo Horizonte, v. 11, n. 1, p. 173-194, 2015.

ZAPPEN, J. The Rebirth of Dialogue: Bakhtin, Socrates, and the Rhetorical Tradition. New York: State University of New York Press, 2004. 